\title{
UNA ESPECIE NUEVA DE OPUNTIA DEL ESTADO DE QUERETARO
}

\author{
Emiliano SANChez M. \\ Centro de Bio-Ingeniería \\ ITESM-Campus Querétaro \\ Apartado Postal 37 \\ 76130, Querétaro, Querétaro \\ Y \\ Jose LUIS VILLASEÑOR \\ Instituto de Biología, U.N.A.M. \\ Departamento de Botánica \\ Apartado Postal 70-367 \\ 04510 México, D. F.
}

\section{RESUMEN}

Se describe e ilustra una especie nueva de la familia Cactaceae, Opuntia elizondoana, del estado de Querétaro. Se discuten sus afinidades con $O$. decumbens y $O$. puberula, asimismo se aportan datos sobre su distribución, habitat y características morfológicas que las distinguen.

\section{ABSTRACT}

A new species of Cactaceae, Opuntia elizondoana, from the state of Querétaro, is described and illustrated. Its affinities with $O$. decumbens and $O$. puberula are discussed, as well as data about their distribution, habitat and morphological characters distinguishing them are provided.

Como resultado de las colectas intensivas llevadas a cabo para el programa de catalogación y conservación de las cactáceas del estado de Querétaro, se descubrió una especie nueva del género Opuntia, la cual se describe e ilustra a continuación.

Opuntia elizondoana E. Sánchez et Villaseñor, sp. nov. (Fig. 1).

O. decumbenti et $O$. puberulae affinis, sed cladodiis ellipticis vel oblongis, glabratis et fructibus flavis differt.

Arbusto bajo, 30-65 $\mathrm{cm}$ de alto, extendido, ramificado desde la base; artículos basales de color amarillo, aunque en la época seca toda la planta presenta un tono amarillento. Artículos 1.1-1.5 cm de grosor en la parte media, 10-15(-20) cm de largo, 4.5- 


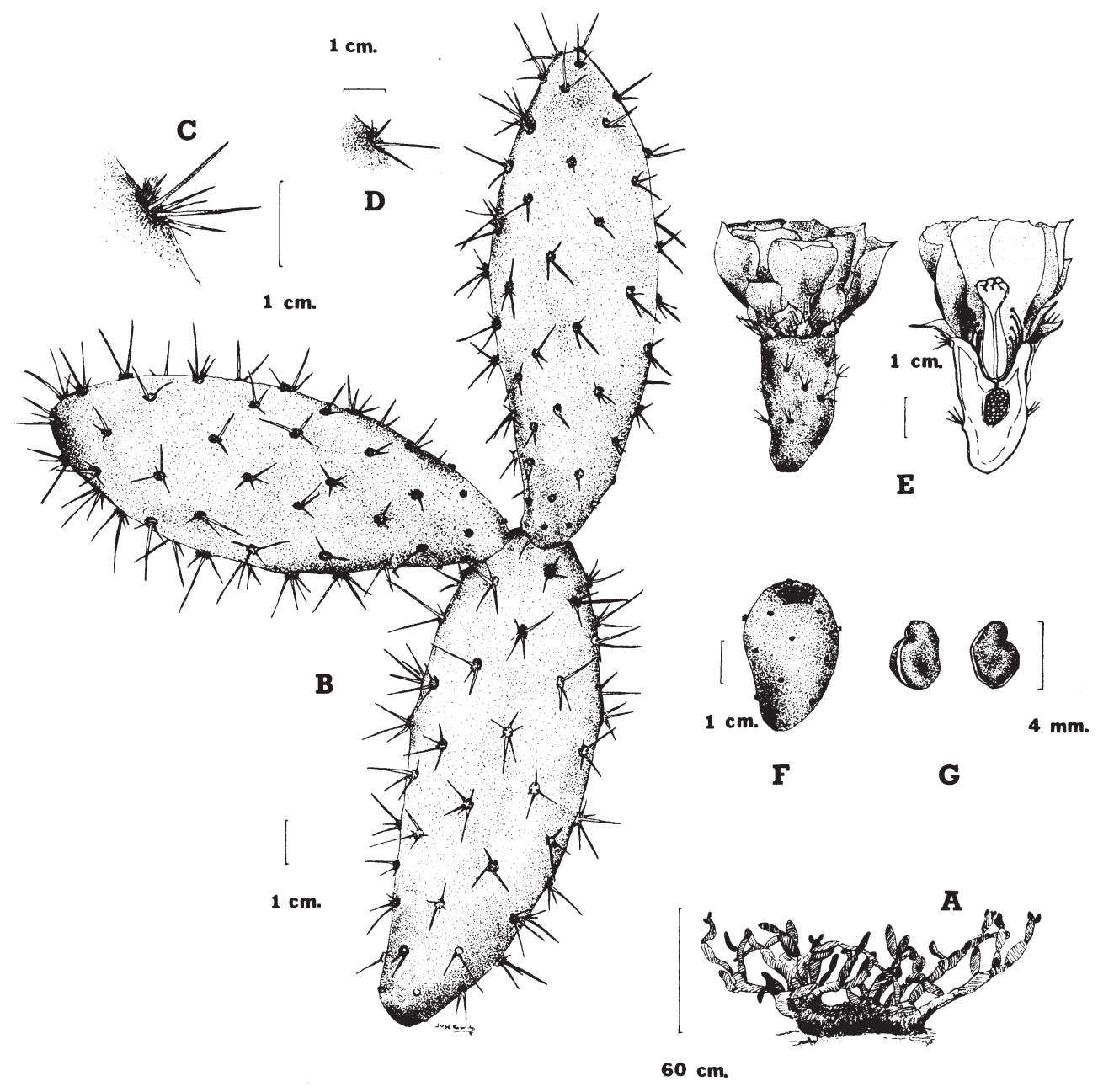

Fig. 1. Opuntia elizondoana sp. nov. A. Hábito; B. Artículos; C. Aréola; D. Epidermis mostrando la condición glabra del artículo; E: Flor; F: Fruto; G: Semilla. (Ilustración por Roberto Martínez Romero). 
5.5. $\mathrm{cm}$ de ancho, de color verde claro a verde olivo, elípticos a oblongos, en ocasiones obovados, algo cuneados en la base, glabros, desprendiéndose con cierta facilidad. Aréolas ovales, blanco-grisáceas, con una mancha purpúrea conspicua en la parte inferior, la cual tiende a desaparecer en la época de lluvias; distancia interareolar (1.1-)1.5(-1.7) cm; glóquidas pardo-amarillentas en la parte superior; espinas 2-3(-4), en ocasiones 6-7 en las aréolas de los artículos basales, las más largas 1.5-1.8(-2.0) cm de largo, las más cortas 0.8-0.9(-1.0) cm de largo, algo divergentes, blanquecinas pero con el ápice pardoamarillento, los artículos jóvenes y los de la porción media de la planta con 2 minúsculas espinas setosas, las cuales se desprenden con facilidad. Artículos jóvenes con hojas pequeñas, amarillentas, con la punta rojiza, caedizas, con 2 espinas por aréola, blanquecinas, con la base rojiza y el ápice amarillento. Flores con segmentos del perianto escasos, amarillos, con tintes rojizos, los interiores alrededor de $2.5 \mathrm{~cm}$ de largo y $1.2 \mathrm{~cm}$ de ancho, obovados o angostamente obovados, los exteriores alrededor de $2.4 \mathrm{~cm}$ de largo y $1.6 \mathrm{~cm}$ de ancho, angostamente deltoides o romboides, mucronados; estambres numerosos, más cortos que los segmentos del perianto, los filamentos blanquecinos, las anteras de color blanco-crema, con tintes rojizos; estilo alrededor de $2 \mathrm{~cm}$ de largo, blancoverdoso, con tintes rojizos en la unión con los estigmas, la base ensanchada, estigma verdoso, con 8 lóbulos de alrededor de $4 \mathrm{~mm}$ de largo; pericarpelo alrededor de $3.2 \mathrm{~cm}$ de largo y $1.9 \mathrm{~cm}$ de ancho, alrededor de $1.3 \mathrm{~cm}$ de la base a la cavidad del ovario y paredes de aproximadamente $0.5 \mathrm{~cm}$ de ancho, verdoso, con alrededor de 22 aréolas grisáceas, con glóquidas castaño-parduscas, más grandes y numerosas hacia la base del receptáculo, donde se observan pequeñas brácteas de menos de $5 \mathrm{~mm}$, verdosas, con el ápice rojizo; cavidad del ovario de cerca de $0.8 \mathrm{~cm}$ de largo; receptáculo alrededor de $0.9 \mathrm{~cm}$ de largo. Frutos pequeños, $3.0-3.5 \mathrm{~cm}$ de largo, carnosos, obovoides, umbilicados, algo cartilaginosos, de color verde oscuro cuando inmaduros, blanco-amarillentos o tendiendo a color salmón cuando maduros, glóquidas escasas. Semillas alrededor de 4 $\mathrm{mm}$ de diámetro, blancas, semiorbiculares.

TIPO: MEXICO: Querétaro. En la cañada de Menchaca, al norte de la ciudad de Querétaro; bosque tropical caducifolio perturbado, con Stenocereus dumortieri; alt. 18501900 m, 5 Junio 1990, E. Sánchez M. y G. Galindo 4 (holotipo MEXU; isotipos: IEB, SLPM).

Opuntia elizondoana es un miembro de la serie Tunae (Schumann) Britton \& Rose, que incluye arbustos bajos, postrados, con tronco más o menos bien definido, con artículos que se desprenden aunque no con relativa facilidad, en ocasiones con una mancha purpúrea rodeando a la aréola y fruto carnoso (Britton y Rose, 1937; Bravo-Hollis, 1978). La serie Tunae incluye unas 12 especies que se distribuyen en México, Guatemala, las Antillas y el norte de Sudamérica.

Opuntia elizondoana está relacionada con $O$. decumbens Salm-Dyck y con $O$. puberula Pfeiff., las tres especies compartiendo la mancha purpúrea circundando las aréolas. Sin embargo, se diferencia de ellas por la condición glabra de sus artículos y por el color amarillento de sus frutos maduros. En las otras dos especies los artículos son tomentosos y los frutos maduran en un tono rojo-purpúrea. En el cuadro 1 se destacan las diferencias más notables que distinguen a estas especies. 
Acta Botánica Mexicana (1994), 27:1-5

Cuadro 1. Características diagnósticas de Opuntia bella, O. decumbens, O. puberula y O. elizondoana.

\begin{tabular}{|l|l|l|l|l|}
\hline CARACTER & O. bella & O. decumbens & O. puberula & O. elizondoana \\
\hline $\begin{array}{l}\text { Mancha purpúrea en } \\
\text { torno a la aréola }\end{array}$ & Ausente & Presente & Presente & Presente \\
\hline $\begin{array}{l}\text { Artículos pubescen- } \\
\text { tes }\end{array}$ & No & Sí & Sí & No \\
\hline $\begin{array}{l}\text { Color de los artícu- } \\
\text { los }\end{array}$ & Verde oscuro & Verde-amarillento & Verde & $\begin{array}{l}\text { Verde claro a } \\
\text { verde olivo }\end{array}$ \\
\hline $\begin{array}{l}\text { Forma del artículo } \\
\text { Ooblongo }\end{array}$ & Anchamente obovado & $\begin{array}{l}\text { Angostamente } \\
\text { oval }\end{array}$ & $\begin{array}{l}\text { Elíptico a } \\
\text { oblongo }\end{array}$ \\
\hline $\begin{array}{l}\text { Color del fruto ma- } \\
\text { Verde-amarillento }\end{array}$ & Rojo-purpúreo & Rojo-purpúreo & Amarillo \\
\hline
\end{tabular}

Opuntia elizondoana es conocida únicamente de una cañada situada al norte de la ciudad de Querétaro, creciendo en los remanentes de un bosque tropical caducifolio, actualmente dominado por Stenocereus dumortieri (Scheidweiler) Buxbaum e Ipomoea murucoides Roem. \& Schult. O. decumbens y O. puberula son también características del bosque tropical caducifolio, la primera conocida sólamente de los estados de Guerrero, Oaxaca y Puebla, y la segunda ampliamente distribuida en las vertientes tanto del Océano Pacífico como del Golfo de México.

Siguiendo la clave para los miembros de la serie Tunae, propuesta por Britton y Rose (1937), Opuntia elizondoana podría ser identificada como O. bella Britton \& Rose, una especie conocida sólamente para la región occidental de Colombia. Sin embargo, $O$. elizondoana difiere de ella por no presentar los artículos repandos o las aréolas elevadas y con tomento, así como por ser una planta más baja.

El epíteto específico rinde homenaje póstumo al eminente cactólogo Jorge L. Elizondo, de la Universidad Autónoma Agraria "Antonio Narro", prematuramente fallecido en marzo de 1989.

\section{AGRADECIMIENTOS}

Las siguientes personas han tenido una participación determinante en la culminación de esta publicación: Dr. Emiliano Sánchez Flores, C. P. Martha R. Figueroa Escobar, Ing. Roberto Martínez Romero, Técnico Agrícola Juan Gabriel Lagunas Solís, Dra. Leia Scheinvar y Biólogos Susana Gama y Salvador Arias; a todos ellos nuestro reconocimiento. El trabajo de campo ha sido posible gracias al apoyo del ITESM-Campus Querétaro. 
Sánchez y Villaseñor: Una Especie Nueva de Opuntia de Querétaro

\section{LITERATURA CITADA}

Bravo-Hollis, H. 1978. Las Cactáceas de México. Universidad Nacional Autónoma de México. México, D.F. Vol. 1.

Britton, N. L. y J. N. Rose. 1937 [Reimpresión 1963]. The Cactaceae. Second edition. Dover Publications. Nueva York. Vol. 1. 